\title{
«Tachadlos», proscriptos y escindidos. El lencinismo en los inicios de la Era Demócrata (Mendoza, 1930-1934)
}

\section{Disenfranchised, banned and factionalized. The "lencinismo" at the beginning of "Demócrata" Era (Mendoza, 1930-1934)}

\author{
Abraham, Andrés
}

Andrés Abraham rabraham@mendozaconicet.gob.ar Universidad Nacional de Cuyo- Instituto de Ciencias Humanas, Sociales y Ambientales, Consejo Nacional de Investigaciones Científicas y Técnicas (INCIHUSA - UNCuyo-CONICET), Argentina

Estudios Sociales. Revista Universitaria Semestral Universidad Nacional del Litoral, Argentina

ISSN: 0327-4934

ISSN-e: 2250-6950

Periodicidad: Semestral

núm. 61, e0003, 2021

estudiossociales@unl.edu.ar

Recepción: 10 Julio 2020

Aprobación: 26 Abril 2021

URL: http://portal.amelica.org/ameli/jatsRepo/293/2932743003/ index.html

DOI: https://doi.org/10.14409/es.2021.2.e0003

El contenido está bajo Licencia Creative Commons AtribuciónNoComercial-Compartir Igual 4.0 Internacional. Atribución - No Comercial - Compartir Igual (BY-NC-SA): no se permite un uso comercial de la obra original ni de las posibles obras derivadas, la distribución de las cuales se debe hacer con una licencia igual a la que regula la obra original

\section{(c) (2)}

Esta obra está bajo una Licencia Creative Commons AtribuciónCompartirIgual 4.0 Internacional.
Resumen: Con el golpe de Estado del 6 de septiembre de 1930 llegó a Mendoza una intervención federal, encabezada por el nacionalista José María Rosa (hijo), que duró hasta febrero de 1932. Luego asumió la gobernación el demócrata Ricardo Videla, quien gobernó hasta 1935. Ambos gobiernos procuraron restringir al máximo la participación política y las chances electorales de la Unión Cívica Radical Lencinista y de las facciones yrigoyenistas a nivel local. El presente trabajo busca analizar los mecanismos utilizados por ambos gobiernos para impedir la acción política del lencinismo y reconstruir cuál fue la respuesta de dicho partido ante tales trabas. Se pretende matizar con ello el peso relativo del fraude electoral en los distintos comicios del período, respecto de otras cortapisas institucionales y argucias legales, o bien la apelación a otro tipo de restricciones paraestatales como la violencia política.

Palabras clave: lencinismo, proscripción, fraude electoral, década del treinta, partido demócrata nacional.

Abstract: With the coup of september 6, 1930, a new federal intervention arrived in Mendoza, led by the nationalist José Maria Rosa (son). His term extended until february 1932, when the democrat candidate Ricardo Videla took office. Both governments sought to restrict the political participation and electoral chances of the «Union Civica Radical Lencinista», and also restricted the action of other «radical» political groups. This paper seeks to analyze the mechanisms used by both governments to restrict the political actions of the «Lencinist» party and reconstruct what was the response of said party. The aim is to relativize the use of electoral fraud in the different elections of the period, with respect to other institutional breakdowns and legal arguments used by the governments of these years, and also the appeal to other types of parastatal restrictions, such as political violence.

Keywords: «lencinismo», proscription, electoral fraud, thirty years, «partido demócrata nacional». 


\section{Introducción}

La década de 1930 viene siendo revisitada con nuevos bríos en los últimos años, manifestándose particular interés entre los historiadores respecto de aspectos clave como la dinámica de los partidos políticos o la competencia electoral a lo largo del período $1930-1943^{[1]}$. De igual manera, la reducción de la escala de observación desde los escenarios nacionales a marcos regionales, provinciales o locales ha permitido matizar ciertas afirmaciones plausibles para el espacio nacional y complejizar el abordaje al interior del mosaico de partidos que protagonizaron la vida política en todo el mapa electoral argentino (Lichtmajer y Parra, 2014).

Para el orden nacional se destacan los estudios clásicos de Ciria (1964), Cantón, Moreno y Ciria (1980) y Macor (2001), que explicitaron los aspectos salientes de la dinámica político-partidaria, la estructura de la coalición oficialista y las trayectorias de la oposición ${ }^{[2]}$. Otros abordajes apuntaron al fraude electoral y el problema de la legitimidad para explicar tanto los derroteros partidarios como el sustento político de los gobiernos del período ${ }^{[3]}$. Por otro lado, existen estudios en clave sub-nacional que permiten reflexionar sobre cómo se imbricaron estos factores con las particularidades provinciales y las dinámicas de competencia electoral a nivel local ${ }^{[4]}$.

En lo que respecta a la provincia de Mendoza, la historiografía local ha puesto énfasis en el legado de la obra pública o la labor educativa y cultural de las gestiones demócratas e igualmente en su vocación institucionalista, caracterizada por el respeto de las formalidades republicanas y la reactivación de la arena parlamentaria local (Scalvini, 1965; Martínez, 1979; Lacoste, 1991; Cueto, 1999).

Otros estudios específicos reconstruyeron el abanico de partidos existente y las dinámicas electorales, destacándose el trabajo pionero de Llaver (1976), quien analizó los documentos partidarios presentados ante la Junta Electoral local en 1931. En el plano partidario, Lacoste $(1991,1993,1994)$ analizó las trayectorias de conservadores, socialistas y radicales en esos años. Por su parte Cueto (1999) abordó las acciones de gobierno y denominó como «neoconservadores» a los dirigentes demócratas del período. Por último, resultan de interés los trabajos de Caroglio (2009, 2017), sobre el desempeño de las fuerzas políticas y el impacto del fraude en las contiendas electorales provinciales entre 1931 y 1937.

A pesar de estos avances, no ha sido abordada la dinámica intrapartidaria y el derrotero del lencinismo ${ }^{[5]}$ como fuerza política en correlación con el marco institucional y la normativa electoral, ni frente a la reconfiguración del sistema de partidos que siguió al derrocamiento de Yrigoyen. Ante tal vacío, es preciso revisitar el escenario político mendocino del primer lustro de la década de 1930, para apreciar el peso de las diversas cortapisas aplicadas a la oposición radical y reconsiderar cómo se sentaron las bases de la hegemonía demócrata en la vida política provincial.

Corresponde señalar que en Mendoza el «demonio» radical era bifronte: por un lado estaban los elencos del yrigoyenismo, que habían ocupado los altos cargos provinciales con la intervención de 1928 y por otro el lencinismo, movimiento 
que había hegemonizado -con fuertes notas personalistas y populistas- el gobierno provincial y los municipios en la década anterior.

Junto con la reconstrucción del escenario de partidos gestado por las restricciones legales se pretende reconsiderar los resultados de 3 elecciones clave del período: 8 de noviembre de 1931; 2 de abril de 1933 y 4 de marzo de 1934 . Ello en vistas a identificar el peso relativo del fraude frente a otras cortapisas y para identificar los ejes que articularon la relación oficialismo-oposición. Por último, se busca reflexionar sobre el impacto de estas restricciones en el derrotero interno del lencinismo y en su desempeño político-electoral en los años treinta.

Cabe advertir que la preponderancia del partido lencinista durante los años veinte estuvo sustentada en liderazgos carismáticos y en acciones de clientelismo y patronazgo, facilitadas por su condición de oficialismo (Rodríguez, 1979). En pos de apuntalar su hegemonía política, recurrieron algunas veces a prácticas fraudulentas -como intimidación con matones, secuestro de libretas de enrolamiento o robo de urnas-y persiguieron reciamente a sus opositores (Lacoste, 1992). Corresponde considerar entonces cómo tales prácticas se resignificaron en los años treinta, cambiando el signo político de «perseguidores y perseguidos».

\section{Las intervenciones federales: todos contra el lencinismo}

El ocaso del tercer gobierno lencinista -encabezado por Alejandro Orfila- vino de la mano de una intervención federal a cargo del radical yrigoyenista Carlos Borzani. Hubo acciones de acoso judicial y policial a sus líderes, además de persecuciones contra periodistas del diario La Palabra ${ }^{[6]}$, detenciones arbitrarias de dirigentes y torturas a los presos políticos lencinistas (Lacoste, 1994).

A fines de 1929 recrudecieron las tensiones entre yrigoyenismo y lencinismo por el tratamiento del diploma de Carlos Washington Lencinas ${ }^{[7]}$ y éste fue asesinado el 10 de noviembre de 1929. Su muerte generó un gran vacío en el partido, dando comienzo a una lucha intestina por la sucesión del liderazgo partidario entre dos de los hermanos supérstites de la familia Lencinas (José Hipólito ${ }^{[8]}$ y Rafael Néstor ${ }^{[9]}$ ) y otros dirigentes de primer nivel, sin que los dos primeros lograran constituir un liderazgo equiparable al de sus familiares fallecidos.

Por otro lado, el escenario electoral favoreció al radicalismo yrigoyenista, beneficiado subrepticiamente por Borzani. El 2 de marzo de 1930 hubo elecciones para diputados nacionales en las que triunfó el candidato de esta tendencia -Alfredo Perrupato- sobre otra facción yrigoyenista y sobre la UCRL, que llevaba como candidato a José H. Lencinas. Se trataba de la primera elección local -no coincidente con una elección presidencial- en la que el lencinismo era derrotado ${ }^{[10]}$. En ese marco, Borzani ganó confianza y convocó a elecciones para gobernador para el 7 de septiembre. Pero un día antes tuvo lugar el golpe contra Yrigoyen, que provocó en Mendoza la asunción del coronel Ergasto Saforcada como gobernador provisional ${ }^{[11]}$.

El nuevo escenario abierto por el golpe septembrino desorientó a los lencinistas. Si bien en un principio aplaudieron el derrocamiento de Yrigoyen tanto por animosidad como porque creyeron ver la oportunidad para retornar al 
poder (Lacoste, 1994)-, pronto entendieron que el nuevo interventor designado por Uriburu -el conservador José María Rosa- no los favorecería.

Rosa arribó a Mendoza y asumió el gobierno provincial el 25 de septiembre y entre otras acciones inaugurales dictó la ley marcial por delitos comunes y dispuso rebautizar con el nombre $\ll 6$ de septiembre» al Rosedal ${ }^{[12]}$. Asimismo, clausuró los diarios Tribuna (radical yrigoyenista) y La Palabra (lencinista), y detuvo a sus directores ${ }^{[13]}$.

Por otro lado, se iniciaron investigaciones sobre el accionar de varios ex funcionarios lencinistas y de la intervención Borzani. La Comisión Investigadora dio a conocer en noviembre una lista de 45 expedientes girados a la Justicia ${ }^{[14]}$. Comenzó así la exclusión del espectro radical -lencinista e yrigoyenista- del juego político local.

\section{El «espíritu» septembrino: las cortapisas institucionales de la intervención rosa}

\section{Las «tachas» al electorado lencinista y radical}

En vistas a la reorganización partidaria, Uriburu dictó diversos decretos en materia electoral. Dispuso la depuración general de padrones electorales antes del 31 de enero de 1931, y estableció que cualquier elector o partido político reconocido podían pedir la exclusión del padrón de ciudadanos denunciados por falso domicilio. Asimismo, el decreto-ley 10368 dispuso igual medida para la eliminación de ciudadanos fallecidos, de los repetidos y de los inhabilitados según Ley 8871 .

En ese marco, el 23 de junio de 1931 Rosa creó una comisión de «Estudio y Depuración del Padrón Electoral de Mendoza». Resultaron elegidos secretario y presidente Luciano Peltier y Cruz Vera, ambos miembros del Partido Liberal (conservador), al igual que el vocal Joaquín Méndez Calzada ${ }^{[15]}$. Si bien otros partidos como el socialismo independiente o los demócratas progresistas fueron invitados a conformar la comisión, no hubo otras incorporaciones ${ }^{[16] .}$

Las acciones de la Comisión apuntaron a la exclusión de electores del padrón provincial, a partir de diversas impugnaciones hechas por el Partido Liberal sobre la base del falso domicilio. En distintas instancias -hasta octubre de 1931- la entidad resolvió y elevó a la Justicia Federal varias listas de electores tachados, salvándose a posteriori algunos casos por el patrocinio letrado del lencinismo y el socialismo.

La depuración discrecional del padrón electoral alcanzó una magnitud considerable. Si bien las fuentes discrepan en cuanto a las cifras, que oscilan entre 17.000 y 21.000 votantes ${ }^{[17]}$, se trata de aproximadamente un tercio del padrón si consideramos los electores y votantes de las elecciones de diputados nacionales de marzo de 1930, cuyo padrón había sido elaborado por autoridades nacionales ${ }^{[18]}$.

La identificación partidaria explícita de la Comisión dio pie a denuncias de la oposición sobre parcialidad en la «limpieza» del padrón. El perjuicio - provocado principalmente a simpatizantes lencinistas- denota más bien la intención de cercenar el derecho electoral de los sectores populares, ampliamente identificados con ese partido, que tenían además mayores dificultades para 
realizar los trámites burocráticos de la índole de los exigidos. Sin duda, la falta de garantías constitucionales y la vigencia del estado de sitio -junto con la persecución policial y judicial a los lencinistas- explican que las denuncias sobre esos atropellos se vieran acalladas por la intervención.

\section{2. «Barajar y dar de nuevo»: la Junta Electoral y el nuevo escenario partidario}

La «cuestión radical» había sido el motor de la revolución septembrina y conjurar su amenaza fue el objetivo primordial del gobierno de Uriburu (De Privitellio, 2001). En Mendoza, Rosa apuntó por igual a lencinistas e yrigoyenistas (atomizados estos últimos en diversos grupos).

Una de las primeras trabas institucionales a la actividad política fue la restricción del derecho de reunión, ejercida en el marco del estado de sitio y la ley marcial a través de la Policía, mediante la denegación de autorizaciones para realizar tanto mítines públicos como simples reuniones partidarias en locales cerrados ${ }^{[19]}$. Asimismo, la intervención dictó una singular disposición que ordenaba la presencia policial en reuniones partidarias, para controlar que los discursos no criticasen los actos del gobierno nacional ni de la intervención, so pena de detener al orador y disolver la reunión. Tal medida generó enérgicas protestas de todo el arco partidario ${ }^{[20]}$.

Por otro lado, el 4 de agosto de 1931 Uriburu dictó un decreto que elevaba las exigencias para el reconocimiento legal de los partidos políticos: debía evidenciarse un carácter «democrático manifiesto» y «licitud de propósitos», un tesoro compuesto por aportes de los afiliados, autoridades internas elegidas por voto directo de estos y plataformas electorales sancionadas con antelación a la definición de candidaturas. En forma complementaria, se estipulaba que las Juntas Electorales nacional y provinciales no computarían los votos para candidatos que hubieran integrado el «depuesto gobierno radical» (Sanguinetti, 1980:1149; Segovia, 2006: 36-37).

En Mendoza, tal decreto abrió camino a un accionar arbitrario de la Junta Electoral provincial, orientado a la exclusión de los partidos «personalistas» o «caudillistas» del juego electoral. Rosa nombró funcionarios de su gobierno para integrarla, dejándola así al mando de simpatizantes del clima de ideas imperante ${ }^{[21]}$. En este contexto se produjo la reconfiguración total del escenario partidario local.

La concesión de la personería fue una herramienta clave de la que se valió la intervención para favorecer a los partidos que simpatizaron con el golpe septembrino y limitar, como contrapartida, la acción política del yrigoyenismo y del lencinismo.

En virtud de las nuevas exigencias legales todos los partidos debieron convocar convenciones, elegir autoridades, sancionar cartas orgánicas, programas y plataformas para solicitar personería y elegir finalmente candidatos a cargos electivos.

La UCR Lencinista celebró su convención en agosto de 1931, ratificando a sus autoridades. Sancionaron una carta orgánica y una plataforma electoral, ambas a propuesta de una Junta Ejecutiva presidida por José H. Lencinas ${ }^{[22]}$. Pero este partido omitió sancionar una declaración de principios «democrática» y la Junta 
Electoral le negó el 9 de octubre de 1931 la personería, a pesar de que ya habían lanzado su campaña. Se argumentó que el carácter personalista del lencinismo era un peligro para la democracia y la estabilidad de las instituciones ${ }^{[23]}$. En concreto, se aludía al predominio absoluto de figuras vinculadas a la familia Lencinas en los años 20 -tanto en el plano partidario como en la función pública-, y a procedimientos irregulares para lograr mayorías en los cuerpos legislativos. Las autoridades partidarias apelaron la decisión en la Justicia, sin éxito.

Por el lado del yrigoyenismo, el faccionalismo cundió con la autocrítica que hicieron algunos dirigentes sobre la intervención Borzani. Un grupo, encabezado por Aníbal Cabrera ${ }^{[24]}$, convocó reuniones excluyendo a los «borzanistas». Hubo una reorganización del partido, se eligieron nuevas autoridades y se sancionaron una Carta Orgánica y una plataforma electoral. En su declaración de principios señalaron que no tolerarían «personalismos», por ser contrarios a «la independencia ciudadana» (Llaver, 1976:43). Luego de una nueva división interna, se presentaron ante la Junta Electoral bajo la denominación «Unión Cívica Radical Tradicional» y postularon a Cabrera para gobernador, siéndoles otorgada la personería.

Ajeno a tal espíritu crítico, otro sector integrado por ex funcionarios de la intervención Borzani solicitó personería luego de realizar una convención en octubre. Proclamaron la fórmula Francisco Evans y Manuel V. Lugones, bajo la sigla «UCR de Mendoza». Pero el sector se atomizó en varios subgrupos y finalmente la Junta Electoral determinó denegarle personería jurídica (Llaver, 1976:46).

Asimismo, se presentó una tercera facción yrigoyenista: el «Radicalismo Rojo», agrupación provincial creada en 1927 a partir del «rubilarismo» ${ }^{[25]}$. Su fórmula fue encabezada por el militar Juan Greco ${ }^{[26]}$. Este partido fue aceptado por la Junta Electoral -a pesar de su evidente adscripción al yrigoyenismo-, probablemente por sus fuertes críticas al lencinismo y su escaso peso electoral.

Finalmente surgió en esa coyuntura un quinto grupo radical, que adoptó la denominación «Antipersonalista», y en 1931 obtuvo personería partidaria, presentando candidatos junto al socialismo independiente (Caroglio, 2017:99).

Otro tema clave fue la orden de abstención dada por las autoridades nacionales del radicalismo, luego del veto de Uriburu a la candidatura de Alvear. En Mendoza, sin embargo, sólo los grupos de Cabrera y Evans enfrentaron la disyuntiva abstencionista ${ }^{[27]}$.

Por el lado de los liberales, luego del golpe septembrino su revitalización vino de la mano de la órbita nacional. En enero de 1931 los conservadores bonaerenses convocaron a la formación de un partido nacional. En abril se reunieron en Córdoba y finalmente se reunió en Buenos Aires una convención, quedando el 1 de agosto conformado el Partido Demócrata Nacional (PDN), reafirmando su apoyo a los ideales del 6 de septiembre (Azzaretto, 1983:81).

El 12 de septiembre se reunió una convención del Partido Liberal local, se adoptó la denominación nacional y se sancionaron un estatuto, una declaración de principios y una Carta Orgánica. Asimismo, se proclamó la candidatura del ingeniero Ricardo Videla -Secretario de Industrias y Obras Públicas de la intervención Rosa- y de Gilberto Suárez Lago - presidente partidario- para las elecciones de noviembre de 1931, así como también candidatos a electores de 
presidente, legisladores y concejales. La Junta Electoral les concedió personería en forma inmediata y su campaña electoral recibió amplio apoyo de la intervención y del gobierno nacional, llegando a contar en su cierre de campaña con la presencia del General Justo.

Desde entonces y hasta 1943, el PDN hegemonizó la política mendocina sin interrupciones. Aunque al principio hubo actuación separada de socialistas independientes y de antipersonalistas, el primero de estos grupos se sumó al PDN -tanto en el plano electoral como en la función pública-, mientras que los segundos se inclinaron por la abstención y luego por el apoyo incondicional a los conservadores.

Por último, fuera del espectro radical, fueron reconocidos el Partido Demócrata Progresista (PDP) y una facción del socialismo local -encabezada por Benito Marianetti y Santiago Castromán-, que obtuvo personería como «Federación Socialista de Mendoza» (FSM) ${ }^{[28]}$. En la coyuntura de 1931 ambos partidos se unieron, replicando para Mendoza la alianza de nivel nacional encabezada por De la Torre y Repetto. Surgió así la candidatura de Luis Silveti (PDP) para gobernador y Santiago Castromán (FSM) para vicegobernador (Lacoste, 1993). En el plano programático manifestaron su rechazo del personalismo y su aspiración a una democracia real, además de pronunciarse públicamente contra las tachas, el fraude y la violencia política.

Dada la acción proscriptiva de la Junta Electoral, las estructuras que hasta septiembre de 1930 tuvieron mayores chances electorales -lencinistas e yrigoyenistas- quedaron fuera de competencia. La negativa al reconocimiento de su personería incidió en forma clave en la reconfiguración del escenario político y favoreció las chances electorales del PDN camino a los comicios de 1931.

Por otro lado, la asunción de los tres poderes locales por la intervención y sus funcionarios -junto con la vigencia del estado de sitio y la ley marcial a nivel nacional y provincial- hicieron que Rosa y sus ministros pudieran influir sin limitación alguna sobre la policía y el sistema judicial en pos de sus intereses políticos. Esta situación se replicó en otras jurisdicciones como la provincia de Buenos Aires, donde el Poder Ejecutivo provincial intervino en la justicia local con el objeto de disciplinar a los jueces y lograr sus objetivos banderizos (Béjar, 2004; 2005).

Junto con las tachas y la persecución policial-judicial, la denegación de la personería partidaria al lencinismo fue la restricción que más afectó su vida partidaria y sus chances electorales. De modo equivalente a lo que sucedió con el radicalismo en el orden nacional, su peso electoral quedó neutralizado y ello se convirtió en un grave problema de «incentivos» para el partido, al no poder traducirse tal peso en cargos, bancas y posiciones institucionales acordes a su fuerza política efectiva (Giménez, 2017:5). Ello facilitó la dispersión de las bases y la migración de dirigentes de base a las filas del PDN, que se nutrieron de terceras líneas o caudillos territoriales lencinistas que vieron en las administraciones demócratas la posibilidad de mantener sus redes clientelares y recursos.

\section{Las elecciones de 1931 y el ascenso del PDN: siguen las cortapisas}

Replicando la directiva de Uriburu, Rosa llamó a elecciones para el 8 de noviembre de 1931, debiendo elegirse en Mendoza 16 electores de presidente 
y vicepresidente; 6 diputados nacionales; gobernador y vicegobernador; 6 senadores y 9 diputados provinciales en cada distrito electoral y concejales en todos los municipios. Desconoció la ley electoral provincial vigente -sancionada por el lencinismo en 1920 - y dispuso aplicar la ley electoral nacional ${ }^{[29]}$.

La Junta electoral reconoció a siete partidos: el Partido Demócrata Nacional; el Partido Demócrata Progresista y la Federación Socialista de Mendoza (como «Alianza Demócrata-Socialista»); la Unión Cívica Radical Antipersonalista y el Partido Socialista Independiente (en alianza); el «Radicalismo rojo» y la Unión Cívica Radical Tradicional ${ }^{[30]}$.

Por su parte los lencinistas denunciaron el rechazo de su personería y decidieron llevar adelante una singular forma de protesta: ordenaron a sus votantes colocar igualmente en las urnas la boleta del binomio Rafael LencinasJorge Calle, como forma de reclamar por su exclusión arbitraria de los comicios (Diario Los Andes, 1982:93). Esto provocó el enojo del interventor Rosa y algunos enfrentamientos entre militantes lencinistas y la Policía en locales de votación.

En las elecciones triunfó el Partido Demócrata Nacional, alcanzando 25.390 votos frente a 10.236 de la alianza Demócrata-Socialista y 2.497 de la alianza PSI-UCR Antipersonalista. El PDN obtuvo la gobernación, la mayoría en los electores de presidente, en diputados nacionales y en los espacios legislativos provincial y comunales (Llaver, 1976).

Entre otras restricciones, en los días previos al comicio hubo impedimentos al derecho de reunión y a la libertad de prensa. El estado de sitio fue levantado el día 8, por lo cual la campaña se dio bajo vigilancia de las fuerzas policiales. A nivel nacional, miembros de la Alianza Demócrata-Socialista denunciaron que el fraude había arreciado en Mendoza y en Buenos Aires, caratulando los comicios de esas dos provincias como «escandalosos»y, al igual que los lencinistas y los radicales rojos en Mendoza, pidieron su nulidad ${ }^{[31]}$. Sin embargo, el gobierno de la intervención adujo la normalidad absoluta de los comicios ${ }^{[32]}$.

\section{Gobierno de Videla: nueva ley electoral, fraude y escisión lencinista}

En febrero de 1932 asumió la gobernación Ricardo Videla, abriendo paso a la normalización institucional de la provincia, bajo la égida del PDN. La Legislatura se conformó en diciembre de 1931, quedando integrada por mayoría del PDN y minoría correspondiente a socialistas y demo-progresistas.

\section{La reforma electoral y su primer test en 1933}

En abril de 1932 el PDN presentó un proyecto para modificar la ley electoral provincial, que databa de la época lencinista ${ }^{[33]}$. La nueva norma -Ley 977- fue publicada en el Boletín Oficial el 10 de octubre de $1932^{[34]}$. Entre las novedades principales incorporó un apartado destinado a los partidos políticos y dispuso la reestructuración de la representación parlamentaria.

El nuevo capítulo sobre los partidos estuvo en sintonía con los decretos de Uriburu de 1931. Se preveía para su reconocimiento la inscripción de 
las agrupaciones ante la Junta Electoral, exigiéndose diversos documentos partidarios ${ }^{[35]}$. El trámite debía reiterarse antes de cada elección, aunque bastaba para las ya inscriptas en 1931 la presentación de acta de renovación de autoridades, plataforma y proclamación de candidatos. Por último, en clara oposición al personalismo, se disponía una singular prohibición de recurrir a nombres de dirigentes vivos para bautizar partidos, comités o sus locales campaña ${ }^{[36]}$.

Respecto de la representación parlamentaria, se dispuso el voto por lista cerrada (no por candidato) y, por el artículo 52, se asignó «la mitad más uno» de las bancas en juego a la lista del partido ganador, quedando la «mitad menos uno» restante disponible para dividir entre «las minorías» que seguían en orden de votos, siempre que alcanzaran el piso mínimo de votos. Esta última distribución debía realizarse mediante el sistema de cociente y por orden estricto de candidatos de cada lista. Conforme a este sistema mixto, la lista triunfante lograba la proclamación de todos sus candidatos, mientras que el escrutinio debía disponer - por medio del cociente- la asignación proporcional del resto de los escaños para las minorías que siguieran en votos ${ }^{[37]}$.

Se vislumbra en el fondo de esta innovación tanto el intento de fragmentar la representación opositora como la necesidad de dotar al oficialismo de una bancada numéricamente sólida, que garantizase el quórum y una posición indiscutible a la hora de proponer, votar y aprobar las leyes requeridas por el Ejecutivo.

En cuanto a la composición de la Junta Electoral provincial, se mantuvo su integración con los jueces de la Corte y las máximas autoridades legislativas ${ }^{[38]}$ y se ratificó su papel preponderante en la organización de los comicios y el juzgamiento de su validez. La novedad estribó en su potestad -ahora legal-para el otorgamiento de las personerías partidarias, punto ampliamente cuestionado por el lencinismo, que sostuvo que la nueva ley electoral fue creada únicamente para «perseguir» y separar de los comicios al partido que en Mendoza era «popular y mayoritario» ${ }^{[39]}$.

El 2 de abril de 1933 hubo elecciones legislativas provinciales para el primer distrito y de concejales bajo la nueva ley. El lencinismo decidió la abstención electoral y lanzó la consigna de «no votar», manifestando que la participación legitimaría el fraude del oficialismo. Un afiche explicativo elaborado por el Comité provincial de la UCRL (figura 1) justificó la abstención con un mensaje moral y patriótico ${ }^{[40]}$.

En tales comicios triunfó el PDN -que obtuvo 8.620 votos- frente a los 3.420 del Partido Socialista y 720 del Partido Demócrata Progresista. Hubo denuncias de fraude e irregularidades de partidos minoritarios reflejadas en la prensa nacional ${ }^{[41]}$, pero que fueron desconocidas por el gobierno. Posteriormente, en la discusión de los diplomas en los recintos de las cámaras se reiteraron y ampliaron tales denuncias, pero el predominio numérico del oficialismo permitió su aprobación y la exposición de argumentos que desconocían irregularidades y brindaban un barniz de normalidad ${ }^{[42]}$. 


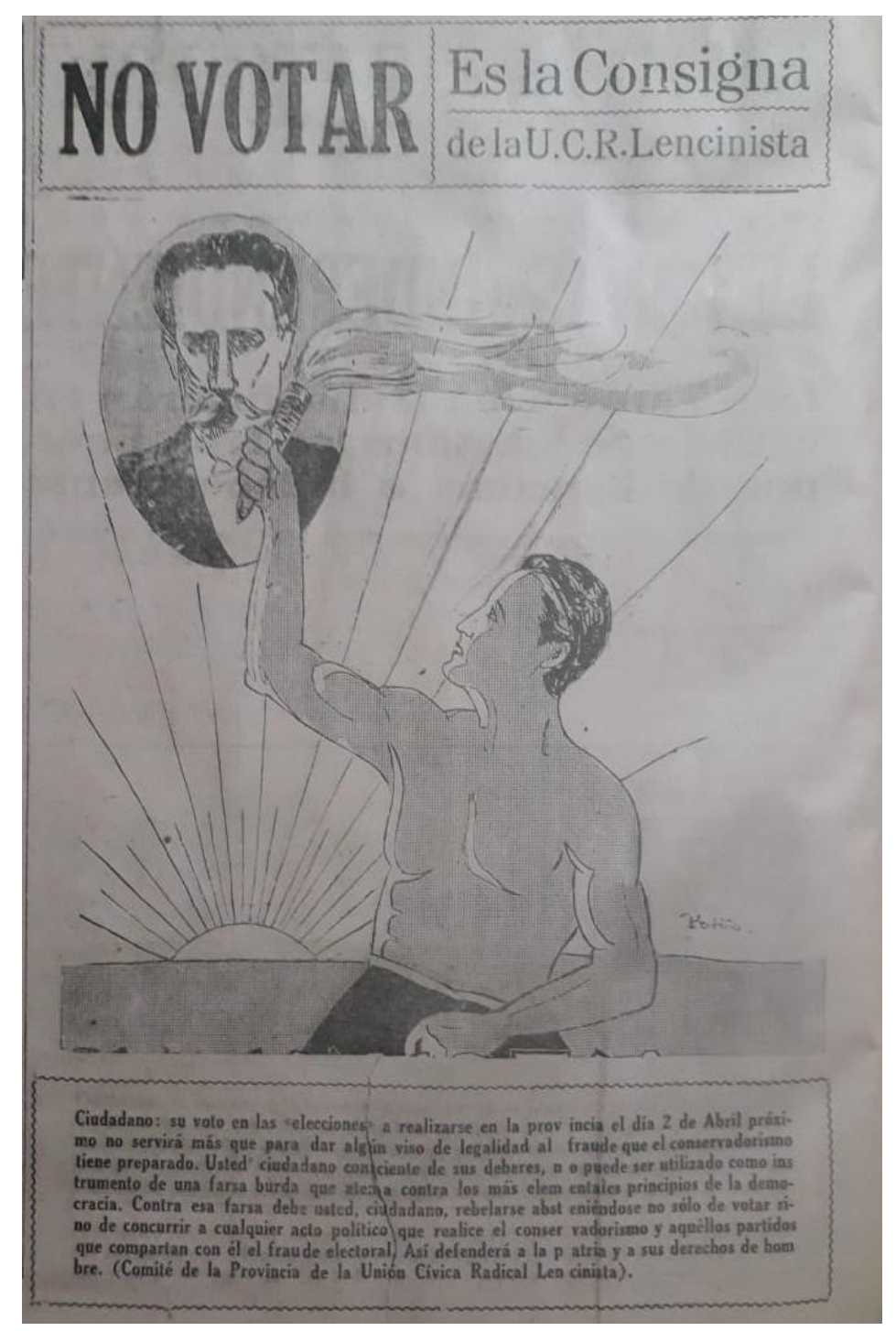

Figura 1.

Afiche de la UCRL.

«La Palabra», 01/02/1933.

En forma complementaria, en octubre de 1933 se sancionaron otras dos leyes sobre cuestiones electorales: la Ley 1022 -que concedía una amnistía a los que no votaron en las elecciones del 2 de abril-y una modificatoria del artículo 110 de la Ley 977. Esta última fue aprobada en la Legislatura sólo con mayoría demócrata, y dispuso sumar 3 escaños a la Cámara de Diputados ${ }^{[43]}$. El objetivo era reforzar la cantidad de bancas del PDN en el marco de la mayoría y alterar el quórum para aprobar las leyes.

Este tipo de modificaciones - hechas sobre la marcha y de manera irregularevidencian la amplia discrecionalidad que tenía el oficialismo local para cambiar las reglas de juego según sus intereses. Pero la persistencia del recurso al fraude en las elecciones posteriores da cuenta de que las restricciones institucionales se presentaban como recaudos insuficientes para los demócratas a la hora de conjurar la amenaza lencinista y garantizar su prevalencia. 


\section{2. «Divide y reinarás»: escisión lencinista, personerias y elecciones en 1934}

A mediados de 1933 tuvo lugar una escisión interna en partido lencinista, a partir de un conflicto originado en el comité de Godoy Cruz ${ }^{[44]}$. Una convención partidaria reunida el 20 de agosto ratificó la remoción de José H. Lencinas y de otros dirigentes solidarizados con este -incluido su hermano Rafael-. Lencinas reaccionó afirmando que el partido era «él» y dispuso echar a todos sus oponentes, empezando por el vicepresidente del Comité provincial, Virgilio Sguazzini (Llaver, 1976:8).

Expulsados los hermanos Lencinas y sus acólitos, el apoderado de la UCRL, Alberto Chacón, solicitó en septiembre a la Junta Electoral la personería partidaria, elevando una síntesis de la disputa interna reciente. Luego de rechazar un primer pedido - por entender que el aditamento «Lencinista» constituía una referencia «personalista»- la Junta les otorgó la sigla «UCRL», argumentando que tal adjetivo era sólo un «homenaje» a dos políticos «ya desaparecidos». Se reconoció como nuevos apoderados a Sguazzini y Chacón ${ }^{[45]}$.

Luego, en enero de 1934, y en vistas a consolidar la ruptura, la Junta Electoral aceptó la petición de personería de la otra facción, presentada por José H. Lencinas y su apoderado Jorge Albarracín Godoy, bajo el nombre de «UCR Federalista» ${ }^{[46]}$. Se argumentó que en su Carta Orgánica manifestaban adoptar un carácter «definidamente democrático, que persigue el ejercicio de una democracia integral en lo social, político, económico y el bienestar de los trabajadores $(\ldots) \gg\left[{ }^{47]}\right.$.

En forma paralela se produjo una división en los órganos de prensa que acompañaban la actividad partidaria: mientras los hermanos Lencinas retuvieron para sí La Palabra, la facción liderada por Sguazzini se expresó a través de las páginas de Libre Palabra y hubo fuertes cruces entre ambos (Lacoste, 1994:140) ${ }^{[48]}$.

En vistas a las elecciones legislativas del 4 de marzo, los dos partidos lencinistas y el socialismo postularon sus candidatos y comenzaron sus campañas. Los «federalistas» recurrieron igualmente al nombre «Lencinista», a pesar de la prohibición de la Junta. Los hermanos Lencinas encabezaron sus listas, siendo Rafael Néstor primer candidato a Diputado Nacional y José Hipólito primer candidato a senador provincial por el tercer distrito (figura 2). En los días previos al comicio los tres partidos denunciaron amenazas y persecuciones por parte de la policía, prohibición de actos proselitistas y secuestros de libretas de enrolamiento. El gobierno, sin embargo, continuó desconociendo ante la opinión pública las diversas denuncias (Llaver, 1976:13). 


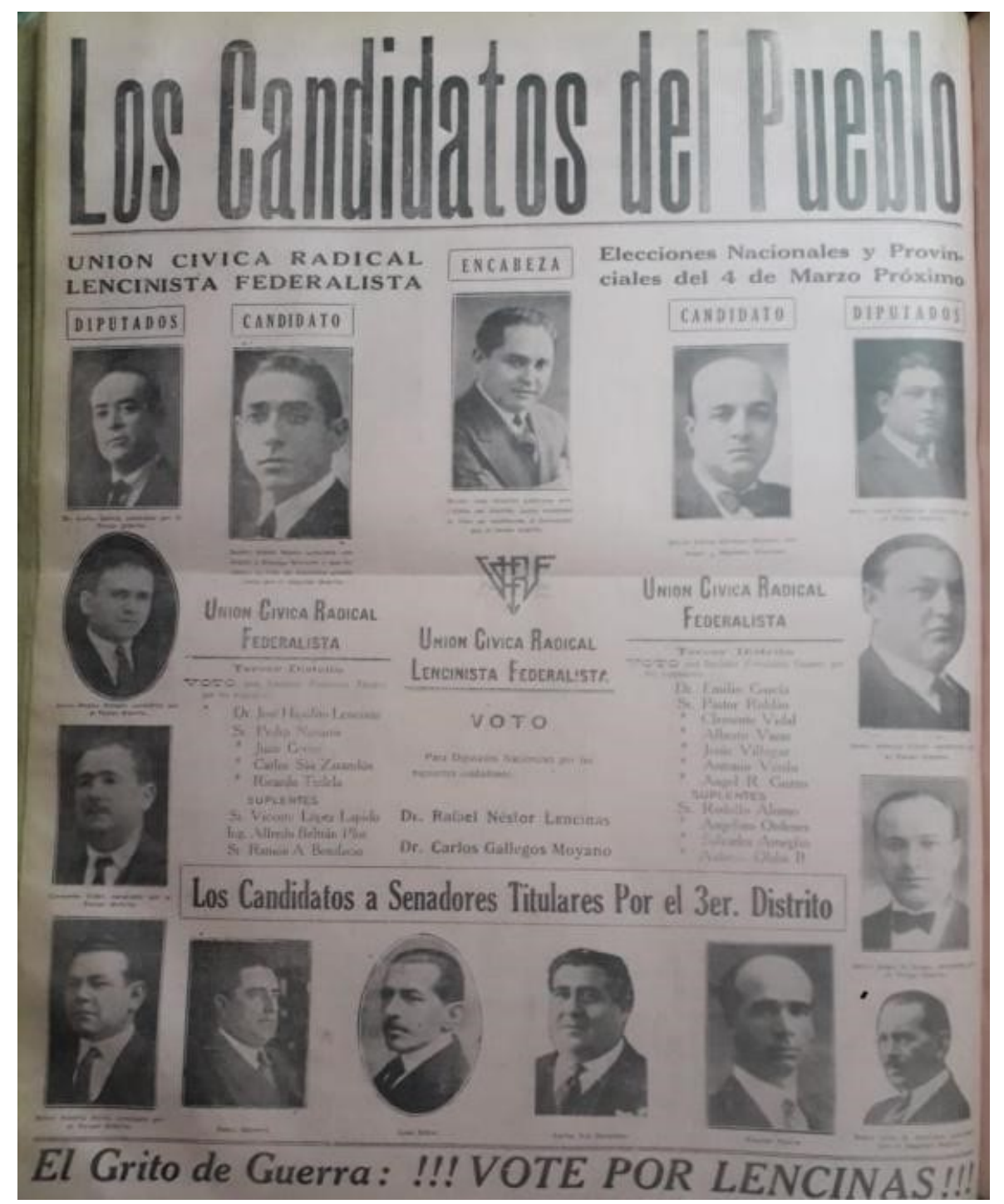

Figura 2.

Afiche publicitario de la UCR «Federalista». «La Palabra», 01/03/1934.

La disputa por la sigla se trasladó al plano nacional, merced a un escrito presentado por la familia Lencinas ante la Junta Electoral Nacional. En él rescataban la figura de los ex gobernadores fallecidos y reclamaban su nombre como un patrimonio propio, que se extendía a su familia más allá de la existencia física de aquellos, acusando a los dirigentes de la otra fracción de usurpadores, «contubernistas» y personas carentes de rectitud cívica. El reclamo, sin embargo, no tuvo ningún efecto ${ }^{[49]}$.

Por otro lado, las juntas electorales nacional y provincial prohibieron colocar retratos, emblemas o figuras geométricas en las boletas, y sobre la base de ello fueron impugnadas por el PDN las boletas de la UCRF y el PDP. En el caso de los «federalistas», se observó que la boleta original contenía un curioso monograma (figura 3) que, si bien contenía la sigla del partido tal como había sido aprobada por la Junta provincial («UCRF»), representaba un corazón y formaba la letra «W» (en referencia a la inicial de Washington, el segundo nombre del ex gobernador Lencinas) ${ }^{[50]}$. 
Probablemente la estrategia habría servido a la camarilla federalista en la disputa con la otra facción por el voto del electorado lencinista -constituido en buena parte por analfabeto- para identificar la boleta «correcta» mediante el monograma, con previa indicación de los dirigentes y punteros locales, procurando así sortear la prohibición de colocar los retratos de los ex gobernadores fallecidos, que solía encabezar sus boletas.

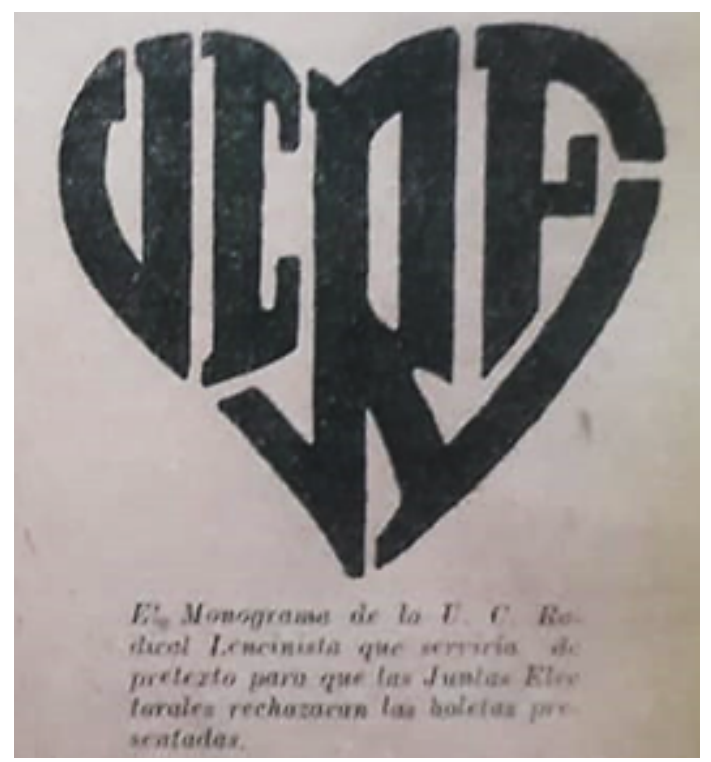

Figura 3.

Monograma que encabezaba la boleta de la UCRF.

«La Palabra», 8/02/1934.

La dilación de la cuestión provocó una airada protesta de José H. Lencinas y la mesa directiva del partido al Ministro del Interior -Leopoldo Melo-, donde señalaban que esto demoraba la impresión y distribución de sus boletas, perjudicando al partido a pocos días de las elecciones. En su telegrama, los lencinistas afirmaron que preferían

«la lucha comicial directa contra el partido oficial, con todas las violencias y fraudes, antes que esta lucha imposible contra las juntas electorales, que con sus expedientes dilatorios silenciosos y sus cuartos intermedios, resultará en definitiva nuestro adversario principal invencible y triunfante» ${ }^{[51]}$.

Con el mismo criterio, y amparados en el artículo 11 de la Ley 8871 (y en su decreto reglamentario de 1916), la Junta Electoral Nacional rechazó también las boletas de la UCR Lencinista por contener las fotografías de los ex gobernadores Lencinas $^{[52]}$.

En los comicios votaron cerca de 55.000 electores, de un total de 77.000 habilitados. Triunfó el PDN, que alcanzó el 43,96\% de los votos, seguido de la UCRF (21,34\%), la UCRL (20\%) y el socialismo $(12,55 \%)^{[53]}$. Una proyección aritmética muestra que las dos siglas lencinistas, en caso de ir unidas, habrían sumado cerca del $42 \%$, alcanzando a los demócratas. Por otro lado, los números evidencian que la cuestión de las tachas perdió peso y que la escisión lencinista fue clave para el triunfo del PDN, aunque ello no implicó que no hubiese irregularidades $^{[54]}$. 


\section{Las cortapisas para-estatales}

A lo largo de toda la etapa analizada, las restricciones institucionales y legales fueron acompañadas de otras formas de coacción. Desde fines de 1930 recrudecieron las intimidaciones y actos de fuerza llevados a cabo por personeros del gobierno, bajo amparo de su posición oficial y de la omisión del accionar policial y la justicia en su castigo. Entre ellas se destacan la amenaza del uso de fuerza contra los lencinistas de parte de la Legión Cívica durante el gobierno de Rosa $^{[55]}$ y por matones a sueldo del Estado durante la etapa neoconservadora ${ }^{[56]}$.

En el plano electoral, el rol de los matones complementó las amenazas a opositores, el secuestro de libretas, la expulsión de fiscales y el «vuelco de padrones». Pero resultó una novedad la implicación de los matones e igualmente de la policía en una forma particular de fraude, consistente en la intimidación de votantes o la inducción del voto dentro del cuarto oscuro (figura 4$)^{[57]}$.

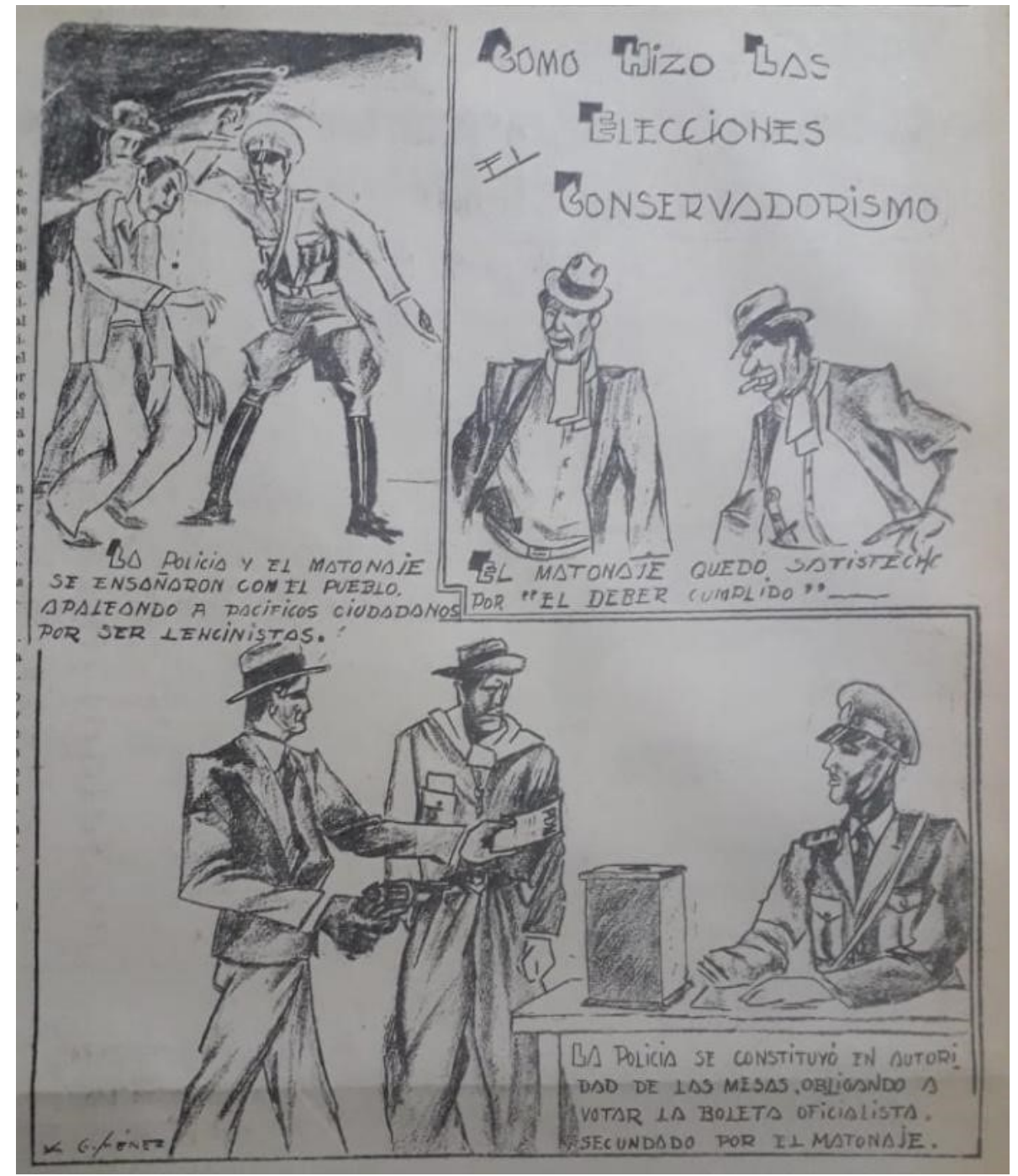

Figura 4.

Representación de la prensa lencinista-federalista sobre las elecciones de 1934. «La Palabra», 15/03/1934.

Otras maniobras fueron la participación de empleados públicos en las campañas electorales a favor del oficialismo y la disolución de actos proselitistas 
opositores por la Policía ${ }^{[58]}$. El primer caso es constatado en diversas denuncias de dirigentes opositores en la prensa, que acusaron al PDN de realizar publicidad con los empleados públicos e incluso de obtener de estos recursos para las campañas en forma coactiva[59].

\section{Conclusión}

Las limitaciones a la participación política de los partidos pertenecientes al espectro radical aplicadas entre 1930 y 1934 permitieron a los gobiernos del Partido Demócrata sentar las bases de su hegemonía en la vida política provincial, que duró hasta 1943. En la integración de la coalición oficialista a nivel local que fue equivalente al orden nacional- el PDN pudo detentar mayor respaldo electoral, frente al carácter insignificante de sus socios socialistas independientes y antipersonalistas. Tal condición le permitió al elenco dirigente local constituirse como un actor de identidad y peso propios dentro del espectro demócrata y del rompecabezas de partidos que integraban la Concordancia a nivel nacional.

La restricción de la participación opositora se llevó adelante en Mendoza con los mismos instrumentos aplicados en el orden nacional y en otras provincias, aunque con distinta magnitud e incidencia. Sin duda resultaron clave las cortapisas institucionales y paraestatales, lo que permite pensar que el fraude electoral no fue indiscriminado y que se aplicó como complemento en forma variable, según el tipo de comicio, los distritos, los partidos que participaban, la percepción del oficialismo respecto de las chances opositoras y los cargos o escaños en juego.

Como pudo verse, en las elecciones de 1931 tuvieron mayor impacto la cuestión de las tachas y la negativa de la personería partidaria, argucias legales que afectaron los vínculos con el electorado y dieron lugar a la proscripción del lencinismo y de la facción yrigoyenista mayoritaria. Lo mismo en 1933, aunque ese año se sumó una reforma electoral como puntal de los intereses del PDN. Hacia 1934, con el lencinismo rehabilitado en sus dos facciones, adquirieron de nuevo importancia las acciones de fraude y la violencia política.

Se vislumbra así que hubo al principio mayor impacto restrictivo de las cortapisas institucionales: depuración de padrones, decretos regulatorios sobre partidos políticos, decisiones de la Junta Electoral y la nueva Ley Electoral provincial, permitiendo a la intervención Rosa primero y luego al gobierno de Videla establecer por vía administrativa o legal las reglas de juego comiciales y adecuar el escenario partidario y electoral a su conveniencia.

Los demócratas aprovecharon su posición de oficialismo y su influencia en las decisiones de la Junta para incidir en la escena política y articular elecciones semi-competitivas; desconocieron denuncias opositoras; modificaron la legislación electoral; utilizaron los recursos estatales a su favor y recurrieron al fraude, acompañando a este último de declamaciones sobre la libertad electoral. Al final del período analizado, promovieron el faccionalismo de la UCRL con el otorgamiento de las personerías partidarias por separado, favoreciendo subrepticiamente a la facción de Sguazzini. Asimismo, a lo largo de toda la etapa, recurrieron al servicio de matones e hicieron uso político de la policía, tácticas que si bien no eran nuevas, se practicaron con mayor impunidad dado el respaldo que le daba al PDN local la situación política nacional. 
El manejo arbitrario de la normativa electoral junto con las restricciones institucionales y paraestatales a la oposición se convierten en la contracara de las gestiones del PDN mendocino en los treinta, caracterizadas en buena parte de la historiografía local por el respeto a las formalidades republicanas, la reavivación de la arena legislativa y su extensa labor en obra pública, cultura y educación. Todos estos aspectos coadyuvaron sin duda a la construcción de la legitimidad indispensable para su dominio político efectivo, tal como advierten Macor y Piazzesi (2005), pero ello no oblitera el vicio de origen de su ascenso y permanencia en el poder provincial.

Respecto del derrotero interno del lencinismo, se constata que -amén de la crisis de liderazgo y del faccionalismo interno-, sus dirigentes no supieron responder a las cortapisas de Rosa y de Videla, haciendo además una lectura errónea de las perspectivas electoralistas que quitó eficacia a sus protestas. La acción impugnadora con boletas no oficializadas de 1931 no se replicó luego: en 1933 se proclamó la abstención con un fuerte discurso moralista, pero después legitimaron -con la concurrencia por separado de los dos partidos- los comicios fraudulentos de 1934 y 1935 , a pesar de las irregularidades antes señaladas. Por otro lado, la falta de vinculación orgánica de este partido con fuerzas de orden nacional -como el Antipersonalismo, con el cual no se registran contactos hasta 1936- implicó su aislamiento en la escena provincial.

Como pudo verse, tanto las restricciones institucionales y para-institucionales como el proceso interno fueron haciendo mella en el caudal electoral de este partido y determinaron su pérdida de relevancia en la escena política, aunque su piso de votos se evidenció casi intacto en las legislativas de 1934.

Por otro lado, las cortapisas limitaron las acciones de resistencia y favorecieron la atomización de la oposición. Junto con ello se desconocieron sus denuncias y se neutralizaron sus acciones de protesta. En ese sentido, debe hacerse hincapié en el rol dinámico de los partidos como actores de la escena política y en la variedad de reacciones a las restricciones padecidas tanto a nivel nacional como local, para matizar el peso del fraude frente a otras limitaciones que restringieron su participación política y a conductas que son responsabilidad de los propios dirigentes opositores.

Asimismo, tal como se mencionó, la práctica del fraude ya tenía antecedentes en la cultura política mendocina. La novedad es que la intervención Rosa y los gobiernos conservadores tuvieron mayor margen de maniobra en las limitaciones legales que implementaron desde su rol de oficialismo, con complicidad de las esferas gubernamentales nacionales, y amparados también en el desprestigio del radicalismo yrigoyenista y del lencinismo ante buena parte de la opinión pública.

En definitiva, se constata la correspondencia para Mendoza de algunos tópicos clave que la historiografía ha debatido para el orden nacional respecto de los años treinta, como las diversas modalidades que adoptó el fraude electoral -en sentido amplio- según las distintas coyunturas comiciales y las jurisdicciones, la sobrerrepresentación de partidos políticos otrora minoritarios en los espacios legislativos y la construcción de legitimidad de los gobiernos fraudulentos por vías alternativas al respaldo electoral genuino. 


\section{Referencias}

AZZARETTO, ROBERTO (1983): Historia de las fuerzas conservadoras, Buenos Aires, CEAL.

BÉJAR, MARÍA DOLORES (2004): «La construcción del fraude y los partidos políticos en la Argentina de los años treinta», en: Cuadernos del CISH, n ${ }^{\circ} 15-16$, pp. 65-97.

BÉJAR, MARÍA DOLORES (2005): El régimen fraudulento. La politica en la Provincia de Buenos Aires, 1930-1943, Buenos Aires, Siglo XXI.

CAROGLIO, ANA VALERIA (2009): «Las contiendas electorales bajo la égida demócrata, Mendoza, 1931-1937», en: Estudios, 22, pp. 75-104.

CAROGLIO, ANA VALERIA (2017): Una historia sobre la relación entre política, prácticas políticas y legitimidad: Mendoza bajo la égida de los gobiernos demócratas, 1932-1943, Tesis de Doctorado, Facultad de Ciencias Políticas y Sociales, Mendoza, Universidad Nacional de Cuyo.

CANTÓN, DARÍO; MORENO, JOSÉ LUIS; CIRIA, ALBERTO (1986): La democracia constitucionaly su crisis, Buenos Aires, Ed. Hyspamérica.

CIRIA, ALBERTO (1964): Partidos y poder en la Argentina moderna (1930-1946), Buenos Aires, Jorge Álvarez Editor.

CUETO, ADOLFO (1999): «El neoconservadorismo en Mendoza (1932-1943). Aproximación a la comprensión de la etapa y de sus hombres», en: Actas del Décimo Congreso Nacional y Regional de Historia Argentina, Buenos Aires, Academia Nacional de la Historia.

DE PRIVITELLIO, LUCIANO (2009): «El imperio de la voluntad popular: el fraude y el estudio de las elecciones en la primera mitad del siglo XX», en: La Fundación Cultural. Ágora, Espacio de Historia y Ciencias Sociales, 38, pp. 57 - 70.

DIARIO LOS ANDES (1982): Cien años de vida mendocina, 1882-1982, Mendoza, Imprenta Hermanos Calle S.A.

GIMÉNEZ, SEBASTIÁN (2017): «Una década de transformaciones en el radicalismo», en: Losada, Leandro (comp.). Política y vida pública. Argentina, 1930-1943, Buenos Aires, Imago Mundi.

HALPERÍN DONGHI, TULIO (2004): La república imposible (1930-1945), Buenos Aires, Ariel.

LACOSTE, PABLO (1991): Los «gansos» de Mendoza. Aportes para el estudio de los partidos provincianos y del modelo conservador, Argentina (1880-1943), Buenos Aires, CEAL.

LACOSTE, PABLO (1992): El lencinismo. Un movimiento populista, Mendoza, Primera Fila, Colección Hechos y Personajes de Mendoza en el siglo XX.

LACOSTE, PABLO (1993): El socialismo en Mendoza y en la Argentina, (tomo 1). Buenos Aires, CEAL.

LACOSTE, PABLO (1994): La Unión Civica Radical en Mendoza y en la Argentina, 1890-1946, Mendoza, Ediciones Culturales de Mendoza.

LLAVER, MARÍA DEL CARMEN (1976): Los partidos politicos mendocinos entre 1930 y 1935, Informe de proyecto de investigación, Mendoza: Comisión Asesora de Promoción de la Investigación, Facultad de Filosofía y Letras, Universidad Nacional de Cuyo, 2 tomos.

LICHTMAJER, LEANDRO; PARRA, MARIA GRACIANA (2014): «Revisando la crisis de los partidos desde una escala provincial. Radicales y conservadores en 
Tucumán (1940-1943)», en: Revista de Historia Americana y Argentina, 49, (1), pp. 1-28.

LÓPEZ, IGNACIO (2012): «La primacía de la política: nuevas visiones historiográficas sobre el sistema político argentino durante los años $30 »$, en: $I V$ Congreso Uruguayo de Ciencia Política, Montevideo, Universidad Católica del Uruguay, 14 al 16 de noviembre.

LOSADA, LEANDRO (comp.) (2017): Politica y vida pública. Argentina, 1930-1943, Buenos Aires, Imago Mundi.

MACOR, DARÍO (2001): «Partidos, coaliciones y sistema de poder», en: Cattaruzza, Alejandro (dir.). Crisis económica, avance del Estado e incertidumbre politica (1930-1943), Nueva Historia Argentina, Tomo VII, Buenos Aires, Sudamericana, pp. 49-95.

MACOR, DARÍO; PIAZZESI, SUSANA (2005): «La cuestión de la legitimidad en la construcción del poder en la Argentina de los años treinta», en: Cuadernos Sur Historia, 34, Bahía Blanca, pp. 9-34.

MARTÍNEZ, PEDRO SANTOS (1979): Historia de Mendoza, Buenos Aires, Plus Ultra.

OVIEDO, JORGE ENRIQUE (2010): El periodismo en Mendoza, Buenos Aires, Academia Nacional de Periodismo.

PIAZZESI, SUSANA (2004): «Una democracia electoral imperfecta. Santa Fe en la primera mitad de la década de 1930», en: Estudios Sociales, 27, pp. 145-169.

PROVINCIA DE MENDOZA (1934). Diario de sesiones de la Honorable Cámara de Diputados. Mendoza: Imprenta La Lucha. Sesiones preparatorias 1933, tomo I.

PROVINCIA DE MENDOZA (1935). Diario de sesiones de la Honorable Cámara de Diputados. Mendoza: Imprenta La Lucha. Sesiones preparatorias 1934, Tomo I.

PROVINCIA DE MENDOZA (1938): Recopilación de leyes, 2da. serie, Leyes sancionadas desde el año 1926 hasta el año 1937, Tomo II, Mendoza, s/d.

RADICALISMO ROJO (1929): Los sucesos de Alvear y la barbarie lencinista, Mendoza, Imprenta Ítalo-Argentina.

RODRÍGUEZ, CELSO (1979): Lencinas y Cantoni. El populismo cuyano en tiempos de Yrigoyen, Buenos Aires, Editorial de Belgrano.

ROSA, JOSÉ MARÍA (1932): Resurgimiento de un pueblo en Mendoza, Buenos Aires, Sociedad Anónima de Impresiones Generales.

SCALVINI, JORGE (1965): Historia de Mendoza, Mendoza, Spadoni.

SANGUINETTI, MIGUEL EDUARDO (1980): «Partidos políticos argentinos. Historia de su régimen legal», en: La Ley, tomo 1980-B, sección doctrina, pp. 1141-1157.

SEGHESSO, MARÍA CRISTINA (1981): «El régimen electoral en la provincia de Mendoza desde la Ley Sáenz Peña a 1930», en: Revista Historia del Derecho, 9, pp. 373-413.

SEGOVIA, JUAN FERNANDO (2006): «La Revolución de 1930. Entre el corporativismo y la partidocracia», en: Revista de Historia Americana y Argentina, 41, pp. 7-50.

\section{Notas}

[1] Para una síntesis de la historiografía sobre el período, véase López (2012) y Losada (2017). 
[2]De la obra de Macor (2001) rescatamos además el balance sobre la preponderancia territorial de las fuerzas oficialistas: mientras el Antipersonalismo era fuerte en Capital Federal y el Litoral (Santa Fe y Entre Ríos) y el Socialismo independiente tuvo una incidencia restringida a la Capital Federal, en el resto de las provincias el predominio correspondió al Partido Demócrata Nacional.

[3]Béjar (2004) y De Privitellio (2009) contextualizan dicha práctica -en el marco de las ideas del momento- como una transgresión necesaria a las reglas de juego para corregir los defectos de la «Ley Sáenz Peña», mientras que Macor y Piazzesi (2005) lo explican a partir de la relación entre reproducción en el poder y producción de legitimidad, en un contexto donde las elecciones constituyeron - al menos hasta 1935- un sistema cerrado a la participación de los partidos de la coalición oficial. Por su parte Halperín Donghi (2004) atribuye las prácticas fraudulentas al fracaso del proyecto de Uriburu y luego a la necesidad de asegurar la permanencia en el poder nacional de la Concordancia o de los partidos situacionistas en los escenarios provinciales, destacando que su ejercicio se apuntaló a nivel institucional por medio de una reforma del reglamento de la Cámara de Diputados - que eliminó la discusión de validez de los diplomas de los recién electos, acto que colocaba a los comicios bajo la lupa de la opinión nacional- y una modificación parcial de la ley electoral, que reimplantaba la lista completa para los electores de presidente, vicepresidente y senadores por la Capital.

[4] Mencionamos, a título de ejemplo, el artículo de Piazzesi (2004), que da cuenta de los dispositivos institucionales que ordenaron la competencia interpartidaria santafesina durante el primer lustro de la década, dando pie a un sistema electoral no viciado por el fraude, pero cuyo trasfondo estuvo dado por la fortaleza del Partido Demócrata Progresista -opositor a la Concordancia-.

[5]El lencinismo fue un movimiento político hegemónico en Mendoza, que ocupó la gobernación en tres oportunidades entre 1918 y 1928. Se gestó en torno a la figura de José Néstor Lencinas (1859-1920), primer gobernador radical en la provincia, y luego a la de su tercer hijo, Carlos Washington (1888-1929), quien en 1921 separó sus huestes del tronco radical y adoptó una identidad partidaria independiente, denominada «UCR Lencinista» (UCRL). Con la intervención federal de 1928 arreciaron las persecuciones del yrigoyenismo y comenzó su declive electoral (Lacoste, 1992).

[6]La Palabra fue un órgano de prensa vinculado al lencinismo, que se publicó hasta fines de los años cuarenta (Oviedo, 2010:161).

[7] Lencinas había sido elegido senador nacional en marzo de 1926, para reemplazar al conservador Benito Villanueva. Pero la aprobación de su diploma se tornó un viacrucis judicial y parlamentario para el dirigente, hasta su rechazo definitivo en el Senado, en septiembre de 1929.

[8] José Hipólito (1896-1978) era el sexto hijo de José Néstor Lencinas. Se graduó de abogado en la Universidad de Buenos Aires y fue secretario de su padre cuando asumió la gobernación. En los años veinte ocupó diversos cargos: fiscal, abogado del Banco Provincia y diputado nacional por la UCRL en los períodos 1923-1924 y 1924-1928. Dentro del partido presidió la Convención provincial y ocupó la dirección de los diarios La Montaña y La Palabra.

[9] Rafael Néstor (1898-1972) era el séptimo vástago de la familia. Se graduó de médico en Buenos Aires, pero nunca ejerció. Fue legislador provincial y presidente de la Cámara de Diputados local. Además, presidió por varios años la juventud lencinista.

[10] Perrupato obtuvo 24.097 votos, frente a 23.997 de Ricardo Báez y a 19.368 de Lencinas (Los Andes, 16/03/1930). El diploma de Lencinas fue rechazado luego en la Cámara de Diputados.

[11]Diario Los Andes (1982).

[12] Este paseo público -inaugurado en diciembre de 1919- llevaba el nombre de Hipólito Yrigoyen.

[13]Oviedo, 2010:209. 
[14] Los Andes, 2/11/1931. El cronista señala que las acusaciones sobre irregularidades administrativas eran «graves» pero «imprecisas». Una situación similar se había dado en 1924 , al asumir la intervención federal de Enrique Mosca (Rodríguez, 1979:272).

[15]Rosa (1932). Peltier pertenecía al Partido Liberal, accedió luego a la intendencia de la Capital en 1931 fue elegido senador provincial por el PDN en 1931 y luego diputado nacional en 1940; Vera era Fiscal de Estado de la intervención, fue elegido senador nacional por el PDN en 1932 y en 1935 asumió como vicegobernador. Por su parte, Méndez Calzada era periodista y había criticado duramente al gobierno de Carlos W. Lencinas. En 1931 asumió como diputado provincial por el PDN, renovando mandato en 1935 y en 1938 fue electo diputado nacional.

[16] El gobierno sólo logró cooptar al socialista independiente Rosendo Vila, quien se integró a la comisión pero fue expulsado de su partido a causa de ello y se sumó al PDN (Lacoste, 1993).

[17] El socialismo local denunció en su periódico la exclusión de 20.000 electores opositores (Lacoste, 1993:98). Por su parte Los Andes alude a 19.000 tachas, conforme a la denuncia del apoderado de la UCR Lencinista ( «Situación de las 19.000 tachas deducidas del padrón electoral de la provincia», Los Andes, 19/11/1931).

[18] En dicha elección hubo 68.301 votantes habilitados («Hay 68.301 votantes inscriptos en el Registro Cívico», Los Andes, 3/03/1930). En cambio en 1931, el padrón fue de 59.863 votantes habilitados, lo que implica una reducción de 8.438 electores respecto de 1930. Para 1934 el número de habilitados fue de 77.725 (Caroglio, 2009:93). Si restamos los empadronados de 1931 a este último número, adquiere verosimilitud la denuncia de un número tachas en torno a 18.000. Esto habría implicado, para las elecciones celebradas entre 1931 y 1934, la exclusión de aproximadamente el $30 \%$ del padrón electoral.

[19] A partir del rechazo a un pedido del Partido Demócrata Progresista (PDP) para realizar un mitin, el cronista de Los Andes destacó la rudeza de la medida de la intervención, por cercenar el derecho de reunión y la propaganda política, garantías reconocidas en la Constitución («Las reuniones políticas», Los Andes, 07/01/1931).

[20]«La libertad de palabra en la Provincia de Mendoza», Santa Fe, 07/11/1930. Radicales, lencinistas -e incluso los liberales- plantearon sus quejas al Ministro del Interior.

[21] Mediante un decreto, a fines de octubre de 1930 se nombró a Cruz Vera y al abogado conservador Alberto A. Day como miembros de la Junta («Ha sido integrada la Junta Electoral de la Provincia», Los Andes, 24/10/1930). El tercer integrante fue el presidente de la Suprema Corte, el conservador platense Luis Reyna Almandos (1874-1939), quien había escrito dos libros con críticas furibundas al primer gobierno de Hipólito Yrigoyen. Por último, se nombró secretario al afiliado conservador Armando Guevara Civit, quien se desempeñaría luego como diputado provincial y como vicegobernador (1938-1941).

[22] Otras figuras clave de la UCRL quedaron fuera de la reorganización por hallarse detenidas. Rafael Néstor Lencinas- ya lanzado como candidato a gobernador- fue apresado en agosto de 1931 en la Capital Federal, acusado de robar documentación policial relativa a las tachas («El Dr. Rafael N. Lencinas reclama por su detención», Los Andes, 2/09/1931). Si bien fue luego liberado, siguió bajo estrecha vigilancia policial. Otros dirigentes procesados fueron Carlos Saá Zarandón ex vicegobernador de Orfila-, Fausto Alfonso - ex candidato a vicegobernador en 1930-y Vicente López Lapido - periodista y ex legislador provincial-.

[23] Señala el dictamen de la Junta que «los propósitos de este partido no son lícitos ni democráticos. Esto puede comprobarse en la Legislatura y en los comicios» (LLaver, 1976:15).

[24] Cabrera era un antiguo dirigente radical que se desempeñó como Diputado y Senador provincial y fue presidente del Comité Provincial de la UCR y delegado al Comité Nacional. Resultó electo diputado nacional en 1918. En 1919 se distanció de Lencinas por su enfrentamiento con el vicegobernador Delfín Álvarez y desde entonces quedó vinculado al radicalismo «disidente $»$. 
[25] El «rubilarismo» fue una tendencia radical yrigoyenista y antilencinista encabezada por el diputado nacional Francisco Rubilar (1867-1926). Al fallecer este último la agrupación se dispersó, pero en la zona sur de la provincia sus huestes se congregaron en torno a Juan Greco.

[26] Greco era un destacado dirigente yrigoyenista con fuerte predicamento en los departamentos de San Rafael y General Alvear. Había sido perseguido por el lencinismo y en 1928 fue detenido, torturado e incomunicado durante las semanas previas a la elección presidencial del 2 de abril. Al salir en libertad escribió un folleto titulado «Mi vida en la cárcel», donde detallaba los vejámenes a los que fue sometido en su calidad de preso político (Radicalismo Rojo, 1929).

[27] Discrepamos aquí con Caroglio (2009), quien sostiene que la UCRL no acató la directiva abstencionista del Comité Nacional radical, porque dicha fuerza no tenía una vinculación orgánica con la UCR nacional -desde su configuración como partido independiente en 1921-.

[28] Al igual que en el plano nacional, el socialismo local sufrió tres escisiones (1915, 1917 y 1927). Por otro lado, en los años treinta las restricciones al lencinismo y al radicalismo le permitieron ganar bancas en la Legislatura y los Concejos Deliberantes, representación en el Congreso Nacional e incluso la intendencia de Godoy Cruz (Lacoste, 1993).

[29]«Aplicación de las leyes electorales», Los Andes, 26/09/1931.

[30] Ante la proscripción, el grupo denominado «UCR de Mendoza» dispuso finalmente la abstención y su titular -Francisco Evans- denunció públicamente en la prensa las tachas, persecuciones a sus militantes y secuestros de libretas por parte del PDN (véase Los Andes, 5/11//1931).

[31] $\ll$ El acto eleccionario de ayer originó la protesta de varios de los partidos concurrentes a la lucha cívica», Los Andes, 9/11/1931. La UCR Tradicional y la alianza Demócrata-Socialista denunciaron fraude y retiraron sus fiscales de los comicios el mismo domingo. Entre otras irregularidades, se mencionan el voto cantado, la expulsión de fiscales opositores, secuestro previo de libretas, no aceptación de boletas y detenciones ilegales de militantes o dirigentes opositores (Llaver, 1976:58).

[32]Diario Los Andes, 1982:93.

[33] El autor del proyecto fue el senador Peltier.

[34] Seghesso (1981) alude a esta ley, aunque la data erróneamente, ubicándola en 1933. Véase Provincia de Mendoza (1938:9-50).

[35] Entre otros, acta de constitución, carta orgánica, acta asamblearia de renovación periódica de autoridades directivas, designación de apoderados, forma de administración de fondos, plataforma electoral y acta de proclamación de candidatos.

[36] El artículo 16 prohíbe «dar a las agrupaciones, comités o locales de reuniones políticas, el nombre de personas que signifiquen un homenaje en vida», ni designarlas como «presidentes honorarios». Ambas prácticas eran comunes en los lencinistas y los yrigoyenistas.

[37] Si bien Caroglio (2009:80) señala que la norma redujo numéricamente la representación minoritaria, entendemos que no hubo un cambio en tal sentido sino más bien en la «atomización» de esta última, pues se dotaba a la mayoría del 51\% de los cargos, fragmentando la representación de la minoría al aplicar la proporcionalidad sólo para el $49 \%$ restante.

[38] Se mantuvo aquí el criterio de la Ley 589, de 1912, pero sumando a los ministros de la Corte -además de su Presidente-. Numéricamente los «jueces» primaban así por sobre los «políticos». Sin embargo, en 1932 la Junta quedó igualmente integrada por figuras vinculadas al PDN: Gilberto Suárez Lago (vicegobernador); Joaquín Méndez Calzada (legislador provincial, presidente de la Cámara de Diputados) y los jueces Mario Baeza González (afiliado demócrata); Luis Salvador Reta (también afiliado, futuro Ministro de Gobierno) y Ramón F. O'Donnell, asesor del futuro gobernador Cano (Llaver, 1976).

[39] «Protesta por la denegatoria de la Junta Electoral Provincial», La Palabra, 17/01/1934. 
[40] Expresa el aviso: «Ciudadano: su voto en las «elecciones» a realizarse en la provincia el día 2 de abril próximo no servirá más que para dar algún viso de legalidad al fraude que el conservadorismo tiene preparado. Usted ciudadano conciente [sic] de sus deberes, no puede ser utilizado como instrumento de una farsa burda que atenta contra los más elementales principios de la democracia. Contra esa farsa debe usted, ciudadano, rebelarse absteniéndose no sólo de votar sino de concurrir a cualquier acto político que realice el conservadorismo y aquéllos partidos que compartan con él el fraude electoral. Así defenderá a la patria y a sus derechos de hombre» ( $\mathrm{La}$ Palabra, 01/02/1933).

[41] Entre otras cosas, se denunció la afectación de empleados públicos a la campaña oficialista, el uso de automóviles oficiales para movilización de votantes, el rechazo de boletas de la oposición y secuestro de libretas de enrolamiento a empleados públicos y a jubilados de la Caja de Pensión de la Vejez e Invalidez (Llaver, 1976).

[42] Cupo a los legisladores socialistas y del PDP la tarea de dar a conocer las diversas irregularidades, entre ellas la vigencia del estado de sitio, la acción de empleados públicos a favor del PDN, la utilización de un padrón mutilado merced a las tachas y las disposiciones restrictivas de la nueva ley electoral o su interpretación discrecional por la Junta Electoral. Sobre la base de esto, uno de los alfiles del socialismo en Diputados, Benito Marianetti, calificó a los comicios de «ficción política» (Provincia de Mendoza, 1934, sesión del 10/05/1933, p. 33).

[43] Véase suelto en Los Andes, 28/10/1933. Según el cronista, la retirada de la bancada del socialismo en pleno quitó el quórum y por ello la presidencia de la cámara no podía dar por aprobado el proyecto, pues la sesión había caducado. El artículo 110 disponía que la provincia se dividía en 3 secciones electorales y cada una elegía 11 diputados, correspondiendo 6 a la mayoría y 5 a la minoría.

[44] Ante la negativa de las autoridades locales a organizar un mitin por temor a la represión policial, el comité de Godoy Cruz fue intervenido en julio de 1933 por orden del presidente del Comité Provincia, José H. Lencinas. Pero el resto del Comité se negó a ratificar la intervención. Lencinas abandonó ofuscado la reunión y decidió una ruptura. Por su parte, quienes permanecieron en el comité desconocieron la intervención y expulsaron a Lencinas ( «Actividad política. Unión Cívica Radical Lencinista», Los Andes, 19/07/1933).

[45] Resultó clave la declaración de principios presentada, que aclaraba que el nombre «Lencinista» era sólo «un homenaje a hombres muertos que han luchado por la democracia» («Acordóse Personería Jurídica a la Unión C. Radical Lencinista (Comité de la calle 9 de Julio)», Los Andes, 4/10/1933).

[46] El dictamen aceptó la documentación presentada, pero rechazó otorgarles el nombre solicitado inicialmente («Unión Cívica Radical Lencinista Verdadera»), por habérsele dado ya a «otro partido» las tres primeras letras de la sigla («Fue rechazada la solicitud de inscripción formulada por la U.C.R. Lencinista Verdadera», Los Andes, 17/01/1934). La petición siguiente se hizo con el aditamento «Federalista», que fue aceptado.

[47]Llaver (1976:16).

[48] Libre Palabra había aparecido como una voz disidente a la conducción de José H. Lencinas en abril de 1933, siendo su director el dirigente Alejandro Mathus Hoyos, ex secretario de Carlos W. Lencinas (Oviedo, 2010:219).

[49]«La familia Lencinas defiende su nombre ante la Junta Electoral Nacional», La Palabra, $7 / 02 / 1934$.

[50] La cuestión desató también una disputa con la otra facción lencinista, que acusó a los «federalistas» de querer apropiarse de «la inicial que el doctor Carlos Washington Lencinas, en forma personalísima, usaba en todos los actos públicos, en su correspondencia particular, en su firma públicamente conocida y que acostumbraba llevar también en su ropa interior» («Boletas rechazadas. El castigo a la felonía», La Palabra, 16/01/1934). 
[51] «La UCR Lencinista protesta por el proceder arbitrario de las Juntas Electorales», La Palabra, 8/02/1934 y «Cómo la Junta Electoral practica el siniestro plan del conservadorismo», La Palabra, 9/02/1934.

[52] «La Junta Electoral Nacional desaprobó las boletas conteniendo retratos», La Palabra, $10 / 02 / 1934$.

[53]Según una denuncia del apoderado de la UCRL, hubo fraude en un tercio de los lugares de votación («En un 30\% de las mesas se cometieron fraudes», La Palabra, 8/03/1934).

[54] En la Cámara de Diputados provincial el socialismo pidió la nulidad de los comicios y el rechazo de los diplomas sobre la base de irregularidades en los padrones, expulsión de fiscales opositores, robos de libretas o amenazas contra los votantes o fiscales. Igual postura y argumentos similares esgrimieron diputados electos por la UCRL - como Arturo Freites o Rafael Tabanera-, añadiendo denuncias sobre cambios de boletas, «voto en cadena» o el accionar persecutorio de la Policía o de matones del PDN. Por su parte el oficialismo destacó el alto nivel de participación (cercano al 70\%) y remitió a noticias de la prensa para evidenciar la normalidad de la votación, aduciendo que las acusaciones de la oposición no eran respaldadas con pruebas suficientes, además de acusar a las facciones lencinistas de promover el «terror» en los días previos y de instruir el retiro de sus fiscales antes del cierre, al ver que los resultados les eran adversos (Provincia de Mendoza, 1935. Sesiones del 23 y 24/06/1934, pp. 13-101).

[55] En junio de 1931 la UCRL pidió al interventor la «disolución de las legiones cívicas militarizadas» que actuaban por fuera del Ejército (Véase Los Andes, 12 de junio de 1931, p. 5). Por su parte, en octubre la filial Mendoza de la Legión Cívica comunicó públicamente la decisión de «usar la fuerza» para «aventar la sombra del personalismo nacional o local» (Diario Los Andes, 1982:93). En virtud de ello se produjeron diversos incidentes y enfrentamientos armados entre legionarios y militantes lencinistas en las semanas previas a los comicios.

[56] Los matones provenían tanto de la cooptación del aparato represivo paraestatal del lencinismo por el PDN como del reclutamiento de nuevos «guardaespaldas» $\mathrm{y}$ «hombres de acción» en el interior de la provincia, de San Juan, San Luis o Buenos Aires (Lacoste, 1991:83-86).

[57] Testimonios de la época dan cuenta de la presencia de personas armadas en el cuarto oscuro, que ordenaban a los electores qué boleta introducir en los sobres. Se trata de una práctica que habría tenido lugar en zonas de campaña. En virtud del estado actual del conocimiento no es posible comprobar tales aseveraciones, pero su pervivencia en el folklore popular señala de alguna manera que la libertad de sufragio no estaba plenamente garantizada en la práctica.

[58] Por ejemplo el 6 de noviembre de 1931, Rosa informó al Ministerio del Interior que la policía desbarató una supuesta revolución lencinista, deteniendo a sus cabecillas y allanando sus domicilios («Las policías de San Juan y Mendoza abortaron el movimiento revolucionario», Santa Fe, 7/11/1931). Una vez levantado el estado de sitio, dejó de exigirse la autorización previa para realizar mítines y actos públicos. Pero en las zonas rurales hubo amplia discrecionalidad de los comisarios locales y jefes políticos para disolver actos opositores. Lo mismo sucedió a nivel provincial, por ejemplo en 1934, cuando la policía disolvió la convención partidaria fundacional de la UCRL «Verdadera», calificándola de reunión «clandestina» («La Policía Conservadora prosigue en su tarea de persecución hacia los opositores», La Palabra, 22/01/1934).

[59] Véase, por ejemplo, el suelto «La nafta para la campaña electoral la pagan los empleados públicos», La Palabra, 9/02/1934. 